\title{
Road Traffic Accidents Among Drivers in Abu Dhabi, United Arab Emirates
}

\author{
Abdulla Hammoudi, George Karani, and John Littlewood \\ Cardiff School of Health Sciences, Cardiff Metropolitan University, Western Avenue, Cardiff, Wales, UK, CF5 2YB \\ Email: \{abhammoudi, gkarani, jlittlewood\}@ cardiffmet.ac.uk
}

\begin{abstract}
The aim of the study was to evaluate relevant factors related to causes of Road Traffic Accidents, RTAs, among drivers in Abu Dhabi, United Arab Emirates, UAE. A questionnaire was developed and piloted in the UK and UAE. There were two versions of questionnaires distributed, one in Arabic language and the second one in English language. All respondents completed and signed a consent form which included information on their rights to withdraw from the study. Six hundred questionnaires were distributed in Abu Dhabi, with the help of two research assistants, from which 291 questionnaires from 185 males and 106 females were returned. The results have identified a number of factors as causes of road traffic accidents in Abu Dhabi and suggested ways to reduce the high RTAs reported in the country. The paper argues that the government should continue to encourage participation of all relevant stakeholders for RTAs reduction initiatives.
\end{abstract}

Index Terms - traffic, accidents, drivers, Abu Dhabi

\section{INTRODUCTION}

All Gulf Cooperation Council (GCC) countries have significantly higher road traffic accident fatality rates compared with other high-income countries [1],[2]. Road traffic accidents is ranked as the 11th leading cause of death in the world [3] and the main source of disability in developing countries [4].

Over the past years there is a slow progress on the traffic accidents reduction in the United Arab Emirates, UAE. According to the Ministry of interior statistics in Abu Dhabi,[5] 720 people were killed in road traffic accidents in the UAE in 2011 comparing with 826 people killed in 2010. However the fatality reduction rate does not reflect a major change in the rate of road traffic accidents and injuries. The age group 18 to 35 years old constitutes more than $50 \%$ of the total deaths of Emirati citizens in 2010.

From experience of the first author as a police officer working with traffic department in Abu Dhabi, there are an increasing number of traffic accidents in the UAE with young drivers injured and the number of traffic violations increasing. According to the Ministry of interior statistics 2010 a comparison between UAE Emirates show that while the number of population and registered vehicles in Dubai is more than in Abu Dhabi, the number of traffic accidents and injuries is higher in Abu Dhabi than Dubai.

Manuscript received January 1, 2014; revised March 28, 2014.
The cost of traffic accidents injuries is estimated to cost $2 \%$ o Gross National Product, GNP, in high income countries, $1.5 \%$ in middle income countries and $1 \%$ in low income countries [6]-[8]. In general, road traffic accidents cost the global community about US\$518 billion [3], [6].

In the UAE, one fatality road crash case costs around USD 2 million, a severe injury costs between USD 1 to 1.5 million, a medium injury cost about USD 300,000 while a minor injury costs about USD 150,000 [9]. The total cost of road crashes injury treatments in intensive care in Central hospitals in Tawam, UAE, cost about USD 22 million annually [10]

The UAE government is committed to reduce road traffic accidents and make roads safer for all users. The UAE Government is working to increase the safety on the roads through development of strategic plans. According to the traffic department in Abu Dhabi the main road safety project in 2010 was a traffic village in Abu Dhabi at a cost of USD 710,000 and traffic awareness campaigns estimated to cost USD 940,000.

\section{ROAD TRAFFIC ACCIDENTS}

Males are more likely to adopt risky driving behaviours and to be involved in car crashes than their female counterparts[6].

Fig. 1 shows the number of fatalities classified by age groups in Abu Dhabi from 2008- 2010. From the results the highest numbers of fatalities were located in the 16 to 45 years old group.

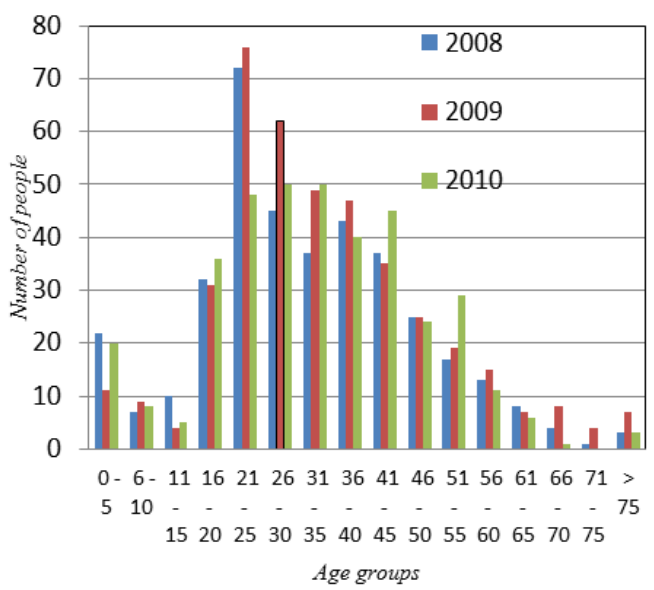

Figure 1. Total number of fatalities classified by age groups in Abu Dhabi between 2008 and 2010. [5] 


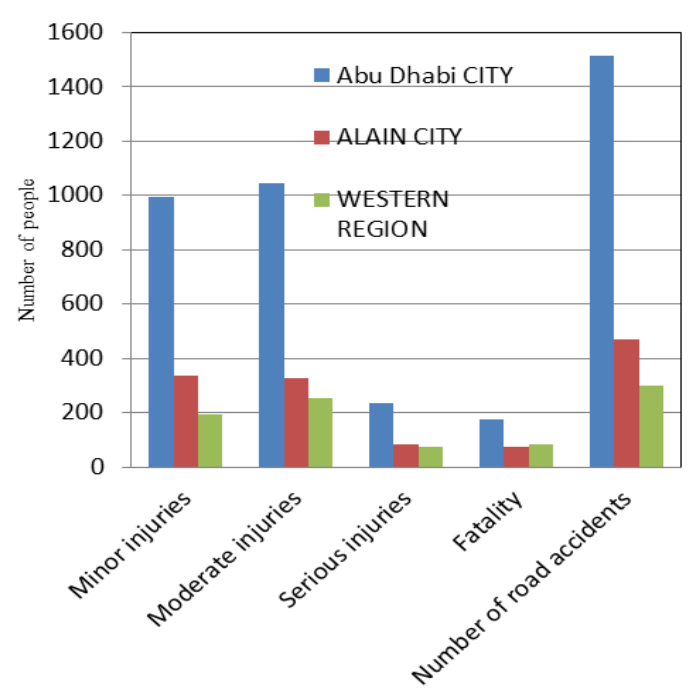

Figure 2. Distribution of the total number of road accidents and injuries in Abu Dhabi region 2011. (Ministry of Interior Abu Dhabi, personal communication, April 15, 2011)

Fig. 2 shows the distribution of the total number of road accidents and injuries in Abu Dhabi region 2011. Abu Dhabi city has the highest number of injuries and accidents compared with other region such as Al Ain and Western regions. Abu Dhabi city has the highest population density, highest number of vehicles and the highest rate of traffic accidents and injuries in Abu Dhabi region.

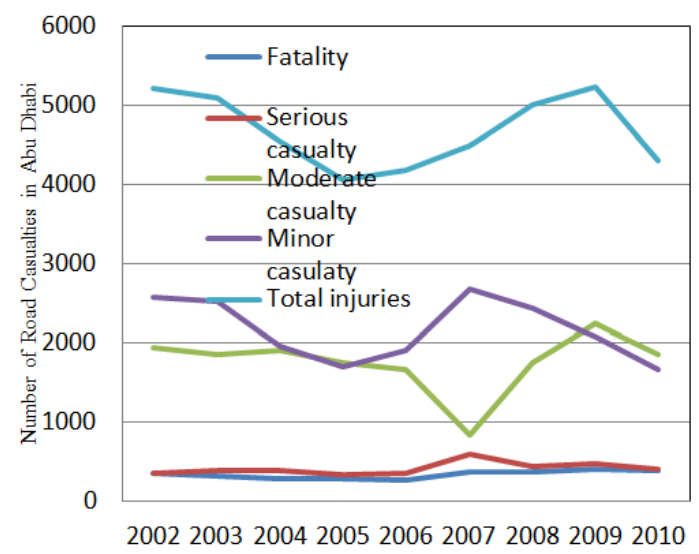

Figure 3. Number of road casualties in Abu Dhabi between 2002 and 2010. [5]

Fig. 3 shows the number of road casualties in Abu Dhabi between 2002 and 2010. The number of fatalities and serious casualties is increasing however the total number of casualties, moderate and minor, is decreasing especially between 2009 and 2010, although further reduction in traffic accidents is required to bring it into levels observed in developed countries

\section{The CAUSES OF TRAFFiC ACCIDENTS IN THE UAE IN 2011}

Traffic accidents are considered to be a major cause of fatalities in the UAE. Table I, below, shows the main causes of road traffic accidents in the UAE, according to the Ministry of interior statistics in 2011
TABle I. CAUSES OF TRAFFIC ACCIDENTS IN THE UAE

\begin{tabular}{|c|c|c|}
\hline Factor & Number of accidents & Percentage \\
\hline Tailgating & 758 & 13 \\
\hline $\begin{array}{c}\text { Lack of appreciation } \\
\text { of other road users }\end{array}$ & 624 & 10 \\
\hline $\begin{array}{c}\text { Entering the road } \\
\text { without checking } \\
\text { whether there are } \\
\text { other vehicles }\end{array}$ & 532 & 9 \\
\hline $\begin{array}{c}\text { Driving through a } \\
\text { red light signal }\end{array}$ & 416 & 7 \\
\hline Driving recklessly & 129 & 2 \\
\hline Tyre explosion & 96 & 2 \\
\hline Others & 3456 & 57 \\
\hline Total & 6011 & $100 \%$ \\
\hline
\end{tabular}

The factors associated with RTA's in the country are comparable to what one would expect in most countries, although a further breakdown of factors under 'other' categories is necessary since that particular category has over half the number of accidents. Other factors identified to contribute to traffic safety include the 4 E's: Engineering, Enforcement, Education and Emergency [11], while human error, vehicle and road network or infrastructure is also a factor in traffic safety reduction [12]. A recent study in the UAE [13] identified driving behaviour, awareness, education and training, infrastructure, vehicle and law enforcement as some of the main factors contributing to traffic safety in the country.

\section{CAse Study City, Abu Dhabi}

The latitude and longitude of Abu Dhabi, United Arab Emirates is: $24^{\circ} 28^{\prime} 0^{\prime \prime} \mathrm{N} / 54^{\circ} 22^{\prime} 0^{\prime \prime} \mathrm{E}$

Abu Dhabi is one of the most modern and richest cities in the world. It is the largest oil producer in the UAE. The Gross Domestic Product (GDP) was estimated in 2009, USD 150 billion [14] which is $60 \%$ of the United Arab Emirates GDP. The population of Abu Dhabi was estimated in 2009 to be about 1.6 million; which is equals to a third of the total UAE population[14]. According to the Ministry of interior statistics in 2010 there were 668,830 vehicles in Abu Dhabi and the length of the Abu Dhabi highways is $2100 \mathrm{~km}$.

\section{METHODS}

Quantitative data method has been used through questionnaire survey as it is documented that around $90 \%$ of road traffic accidents are due to human error. $[6,15$, 16].Drivers were chosen to identify relevant factors that contribute to the traffic accidents in Abu Dhabi.

\section{A. Pilot Survey}

The questionnaire was previously pilot-tested randomly through participants in the UAE and Cardiff. The answers and comments from the respondents were used to complete the final questionnaire survey.

\section{B. Sample Size}

The power calculation was used to calculate the survey sample size for the drivers in Abu Dhabi. 600 drivers 
questionnaire were distributed and 291(49\%) 185 Male and 106 Female were returned.

\section{Data Collection Process}

The data were collected through two field trips in to Abu Dhabi by the first author in December 2011 and March to April 2012.

\section{Plan for Data Collection}

Good planning is very important in research work to minimize errors during data gathering and permission to carry out the research was granted by the relevant authority.

\section{E. Research Assistants}

Two civilian staff -1 male 1 female- working in the Abu Dhabi police traffic department assisted in the data gathering. The two persons had experience on how to deal with the respondents and good interview techniques. They were trained as researchers on method to use in the research work. They distributed the questionnaires and collected the questionnaires after they were completed by respondents and sometimes, if necessary, answered any questions raised by respondents.

\section{F. Questionnaire}

The questionnaire was designed to obtain information regarding driver behaviours and attitudes.

There were two version of questionnaire surveys distributed, one in Arabic language and the second in English language.

All respondents completed and signed a consent form which includes information on their rights to withdraw from the study.

The data has been analyzed using SPSS program.

\section{RESULTS AND DISCUSSION}

Of the 291 driver respondents $63.5 \%$ were male and $36.5 \%$ female, demographic features of drivers indicated in Table II to Table VI.

TABLE II. AGE OF DRIVERS

\begin{tabular}{|c|c|}
\hline Age & Percent \\
\hline Less than 18 & 1.7 \\
\hline $18-25$ & 29.3 \\
\hline $26-35$ & 43.8 \\
\hline $36-50$ & 20.7 \\
\hline $51-65$ & 4.5 \\
\hline & 100 \\
\hline
\end{tabular}

TABLE III. MARITAL Status OF DRIVERS

\begin{tabular}{|c|c|c|}
\hline & \multicolumn{2}{|c|}{ Gender Percent } \\
\hline Marital status & Male & Female \\
\hline Single & 32.8 & 34.9 \\
\hline Married & 63.9 & 56.6 \\
\hline Other & 3.3 & 8.5 \\
\hline & 100 & 100 \\
\hline
\end{tabular}

TABLE IV. MONTHLY INCOME OF DRIVERS

\begin{tabular}{|c|c|}
\hline Monthly income & Percent \\
\hline Less than 2000 AED & 19.2 \\
\hline 2000 to 5000 AED & 13.9 \\
\hline 5001 to 10000 AED & 19.9 \\
\hline 10001 to 20000 AED & 29.3 \\
\hline More than 20000 AED & 13.9 \\
\hline Don't work & 3.8 \\
\hline & 100 \\
\hline
\end{tabular}

TABLE V. EDUCATION OF DRIVERS

\begin{tabular}{|c|c|}
\hline Education & Percent \\
\hline No qualification & 11.1 \\
\hline Less than High school & 10.4 \\
\hline High school & 34.6 \\
\hline Undergraduate degree & 28.0 \\
\hline Post graduate degree & 15.9 \\
\hline & 100 \\
\hline
\end{tabular}

TABLE VI. NATIONALITIES OF DRIVERS

\begin{tabular}{|l|l|}
\hline Nationality & Percent \\
\hline Emirati citizen & 48.3 \\
\hline Gulf Cooperation Council (GCC) countries & 8.0 \\
\hline Other Arab & 24.1 \\
\hline Asian & 15.1 \\
\hline European & 1.4 \\
\hline African & 1.4 \\
\hline Other nationalities & 1.7 \\
\hline & 100 \\
\hline
\end{tabular}

From the data, more than half of the subjects were nonEmirati which is an important factor to consider in traffic safety management for the country. It is necessary to investigate whether there may be a difference in attitudes, perceptions, value in relation to traffic safety between Emiratis and Non- Emiratis.

There are very few published studies on RTA's for people who migrate to other countries and it may be worth considering providing information on traffic rules and regulations to new arrivals in the country. Provision of information packs to new arrivals in a number of countries have been shown to aid in the integration of this group of people, and information on traffic rules and safety has been highlighted by drivers as a necessary information to be included.

The data indicate that more than half of the drivers earn less than AED 10, 000 per month, are married, aged under 35 years and educated at least up to high school.

From the results of the study $49 \%$ male and $34 \%$ female reported that over the last 12 months they had been involved in road traffic accidents. $22 \%$ male and $16 \%$ female reported being involved in non -injuries traffic accidents, while the number involved in injury related traffic accidents was $18 \%$ and $13 \%$ for male and female respectively.

There was a statistically significant relation between being involved in a traffic accidents and gender $(\mathrm{p}=0.014)$, age $(\mathrm{p}=0.024)$ and monthly income $(\mathrm{p}=0.025)$. However, there was no statistically significant relation between being involved in accidents and education or nationalities. 


\section{A. Using a Seat Belt}

According to the European Commission half of injuries and fatalities might be avoided if all cars were fitted with crash protection systems [17]. All vehicles in high income countries have standards regulations for safety such as seat belts, airbags...etc. Failing to wear a seat belt is one of risky driving behaviour and contributes to more fatalities than any other unsafe driving behaviour [18]. A Seat belt prevents around 50\% of being fatality injured in a traffic accident [19].

The seat belt law was implemented in the UAE in 1999 [20], and a seat belt is required for front seat passengers but not for backseat passengers or child restraints.

Drivers who always wear seatbelt while driving were $45 \%$ male and $48 \%$ female, while $14 \%$ male and $13 \%$ female never wear a seat belt while driving. Similar results on seat belt usage were observed when respondents were asked to indicate how frequent they wore seatbelt in the last 7 days. When respondents were asked how often they wore a seatbelt while in a vehicle driven by someone else, $21 \%$ male and $35 \%$ female never wore a seatbelt and only 34\% male and 34\% female always wore a seat belt.

There was a statistically significant relation between wearing seat belt and nationalities $(\mathrm{p}=0.018)$ and monthly income $(\mathrm{p}=0.024)$ However there was no statistically significant relation between wearing seat belt and gender, age or education.

Although there exist a law on seat belt usage in the country, it is a point of concern that a significant percentage of the drivers did not wear a seat belt either while driving or when in someone else's car.

\section{B. Using Mobile Phone While Driving}

According to the University of Utah, using mobile phones while driving will slow ability to brake by up to $18 \%$. Using a mobile phone while driving may cause similar destruction to driving with $0.08 \%$ level of alcohol in the blood[21], and young male drivers have been identified as the most likely to use a mobile phone while driving [22].

From the study, drivers who admitted to use a mobile phone while driving were $21 \%$ male and $22 \%$ female and only $19 \%$ male and $21 \%$ female stated they never use a mobile phone while driving. Similar results on using mobile phones while driving were observed when respondents were asked to indicate how frequent they used mobile phone while driving in the last 2 days.

From the study a very high number of drivers $80 \%$ male and $79 \%$ female- admitted using mobile phones while driving. This is despite the fact that the legislation does not allow using a mobile phone while driving. There was a statistically significant relation between using mobile phone while driving and nationalities $(\mathrm{p}=0.045)$ However, there was no statistically significant relationship between using mobile phone while driving and gender, age, monthly income or education.

It is evident that more work is needed to reduce the number of drivers using mobile phones while driving, and road safety education should be a key component of safety week for all stakeholders. Perhaps there may be merits of investigating whether traffic safety education can be included as part of the school curriculum.

\section{Drink Alcohol and Driving}

According to the UK statistics in 2010, 250 people were killed and 9,700 injured from drink driving[23]. Drink driving accidents can be caused by drivers of all ages. Drinking alcohol reduces the ability for the driver to observe long distance objects by $25 \%$ and reduces the response time for the driver by 10 to $30 \%$.

For example, in France the number of fatalities were reduced by $4 \%$ after lowering the limit to $50 \mathrm{mg}$ of alcohol in per $100 \mathrm{ml}$ of blood [24]. In China the number of drink and driving cases decreased in the area of stricter law enforcement [25]. It is very important to inform and educate people about the penalties of drink and driving. Inclusion of one story in the newspapers on the danger of drink and driving may reduce the number of people who drink and driving illegally [26].

From our survey $17 \%$ of male and $15 \%$ of female drivers admitted to drinking alcohol and driving in the UAE. $6 \%$ male and $4 \%$ female admitted driving a vehicle, one time in the last one month, after drinking alcohol. Very worryingly, $1 \%$ male and $1 \%$ female who were interviewed had, on more than three occasions in the last one month, driven a vehicle after drinking alcohol.

There was a statistically significant relation between drinking alcohol and nationalities $(\mathrm{p}=0.03)$, education $(p=0.01)$ and Monthly income $(p=0.02)$. However there was no statistically significant relation between drinking alcohol and gender or age.

These results were very surprising because traffic accidents statistics in the UAE do not include drinking alcohol as a cause of traffic accidents in the UAE. According to Act 49, Paragraph VII of the Federal Law No. 21 of 1995 Road Traffic Law in the UAE, a driver who drives his vehicle while under the influence of alcohol or drugs will be fined USD 1860, imprisoned for not more than two years and have their driving license cancelled .Further work needs to be carried out to sensitize the drivers and stakeholders on the dangers of drinking alcohol and driving. It should be investigated whether stricter penalties for drink driving could be introduced; including testing drivers for alcohol content after all forms of accidents.

\section{Aggressive Driving Behaviour}

The behaviour of the individual in any place of the world is sometimes affected by the culture and characteristic of society which he lives in. In Abu Dhabi the population consists of around $85 \%$ of people who are non Emirati.

There was $65 \%$ of male and $54 \%$ of female drivers who confirmed that they had adapted to aggressive driving behaviour and $70 \%$ of male and $71 \%$ female admitted to being sometimes very angry to other drivers on the roads. 


\section{E. Unsafe Driving Behaviour}

Speed was ranked first as the most common unsafe driving behaviour by the drivers. $47 \%$ of male and $65 \%$ of female indicated that they had committed speeding violations more often than other types of unsafe driving behaviour. Fig. 4 shows the most common unsafe driving behaviour drivers commit on the roads.

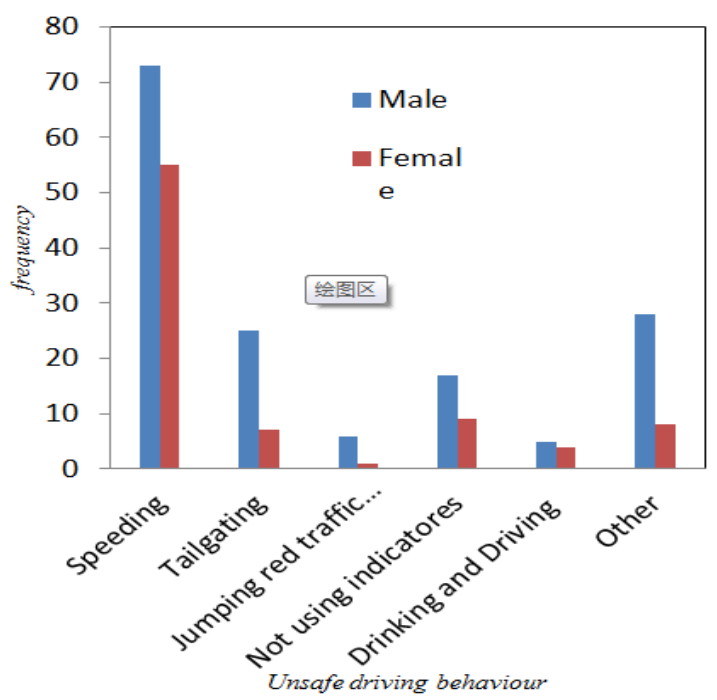

Figure 4. Common unsafe driving behaviours drivers committed on the roads.

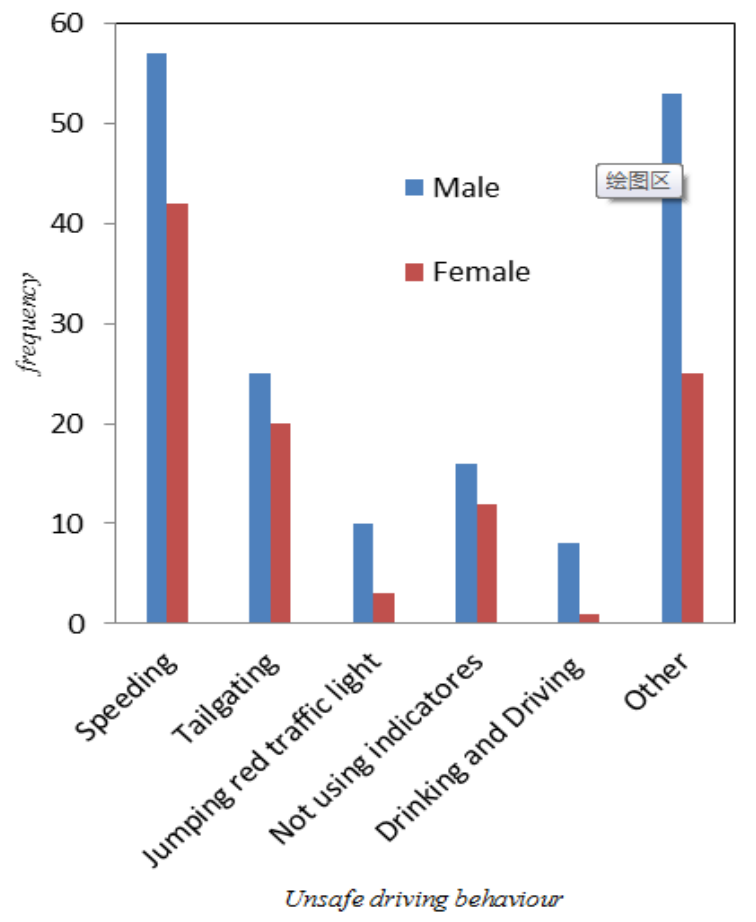

Figure 5. Common unsafe driving behaviours drivers encounter most often on the roads.

Fig. 5 shows the most common unsafe driving behaviour drivers encountered most often on the roads. $33 \%$ of male and $40 \%$ of female indicated that speeding was also the most unsafe driving behaviour encountered on the roads. According to institute for safety research speed controls using radar cars can be effective in increasing road safety [27].
Data presented in Fig. 4 and Fig. 5 demonstrate that there is an association on common unsafe driving behaviours drivers commit and what they encounter while driving.

\section{F. Traffic Campaigns}

$46 \%$ male and $39 \%$ female reported never to have heard about traffic campaigns in Abu Dhabi. 24\% of males would prefer text, twitter and blackberry messengers to be informed of traffic campaigns, while majority of women, $36 \%$, preferred $\mathrm{TV}$ as the main source of traffic campaigns. This is an interesting finding and one that can be used to target specific groups with traffic campaign messages. This would be useful to reduce the number of people who are not aware or not heard of traffic campaigns.

\section{CONCLUSION}

The results of the current study have highlighted a number of issues that require attention in order to reduce traffic related accidents among drivers. It is hoped the information from the study will lead to developing a better understanding of issues related to traffic accidents in the region and hopefully lead to a change in driving habits and unsafe driving behaviors.

Majority of traffic safety projects and strategies focuses on the prevention of car occupants from traffic accidents and only few studies focus on the prevention of vulnerable road users such as pedestrians.

It is suggested that consideration should be given on the development of information packs on road traffic accidents and safety for new arrivals in the country. It is suggested to test alcohol content on all drivers involved in road traffic accidents. Education on traffic safety should be continued and not just during traffic campaigns.

Education traffic safety programs and awareness campaigns should also target children, pedestrians and specific road users such as young drivers. One of the most important things in developing such awareness programs is the collaboration between all traffic safety stakeholders, including transport authority and health authority

\section{ACKNOWLEDGEMENTS}

The authors wishes to thank the drivers who completed the survey, the two assistants who helped with data gathering and the Traffic Department in Abu Dhabi for cooperating with the research team and providing data about traffic accidents.

\section{REFERENCES}

[1] A. K. Abbas, A. F. Hefny, and F. M. Abu-Zidan, "Seatbelt compliance and mortality in the gulf cooperation council countries in comparison with other high-income countries," Annals of Saudi medicine, vol. 31, no. 4, pp. 347, 2011.

[2] A. Bener, T. Özkan, and T. Lajunen, "The driver behaviour questionnaire in arab gulf countries: Qatar and United Arab Emirates," Accident Analysis \& Amp; Prevention, vol. 40, no. 4, pp. 1411-1417, July 2011.

[3] S. Ameratunga, M. Hijar, and R. Norton, "Road-traffic injuries: Confronting disparities to address a global-health problem," The Lancet, vol. 367, no. 9521, pp. 1533-1540, May 2006. 
[4] K. Zimmerman, A. A. Mzige, P. L. Kibatala, L. M. Museru, and A. Guerrero, "Road traffic injury incidence and crash characteristics in Dar es Salaam: A population based study," Accident Analysis \& Prevention, pp. 204-210, May 2012

[5] Ministry of Interior, "Road crashes statistics report 2011," Ministry of Interior: Abu Dhabi, UAE.

[6] S. Sabbour and J. M. Mibrahim, "Driving behaviour, driver style and road traffic accidents among young medical group, in safety 2010," presented at Safety 2010, 10th World Conference, London, September 21-24, 2010.

[7] M. Peden, R. Scurfield, D. Sleet, D. Mohan, A. A. Hyder, E. Jarawan, and C. D. Mathers, "World report on road traffic injury prevention: World health organization geneva," Switzerland, 2004.

[8] T. Toroyan, "Global status report on road safety: Time for action," World Health Organization Geneva, Switzerland, 2009.

[9] Y. Hawas, Personal communication, Road safety center, UAE University, UAE. 2011.

[10] Alittihad. Alittihad News (March 19, 2011). [Online]. Available: http://www.alittihad.ae/details.php?id=26227\&y=2011

[11] J. de Oña, R. O. Mujalli, and F. J. Calvo, "Analysis of traffic accident injury severity on Spanish rural highways using bayesian networks," Accident Analysis \& Amp; Prevention, vol. 43, no. 1, pp. 402-411, January 2011.

[12] G. Chen, "Road traffic safety in African countries - status, trend, contributing factors, countermeasures and challenges," International Journal of Injury Control and Safety Promotion, vol. 17, no. 4, pp. 247-255, June 2010.

[13] M. N. Hassan, Y. E. Hawas, and M. A. Maraqa, "A holistic approach for assessing traffic safety in the United Arab Emirates," Accident Analysis \& Prevention, pp. 554-564, March 2012.

[14] A. Mohammed, S. Ali, and A. Khalid, Abu Dhabi Statistical Yearbook, Statistics Centre, Abu Dhabi, UAE, 2010.

[15] J. P. E. Mearkle, "Road safety fundamentals," Cornell Local Roads Program, New York LTAB Center, September 2009.

[16] WHO, "Global status report on road safety: Time for action," World Health Organization Geneva, Switzerland, 2009.

[17] European Road Safety Observatory. (2006). Vehicle Safety - Web text of the European Road Safety Observatory. [Online]. Available: www.erso.eu
[18] D. M. G. Fernando, A. N. Vadysinghe, N. Sudasinghe, and K. Premasinghe, "Use of seat belts: Prior to the legal requirement," Sri Lanka Journal of Forensic Medicine, Science \& Law, pp. 2325, December 2011.

[19] S. Ma, N. Tran, V. E. Klyavin, F. Zambon, K. W. Hatcher, and A A. Hyder, "Seat belt and child seat use in Lipetskaya Oblast, Russia: Frequencies, attitudes, and perceptions," Traffic Injury Prevention, vol. 13, pp. 76-81, March 2012.

[20] M. D. Munk, D. M. Carboneau, M. Hardan, and F. M. Ali, "Seatbelt use in Qatar in association with severe injuries and death in the prehospital setting," Prehosp Disaster Med, vol. 23, pp. 547-52, December 2008.

[21] D. L. Strayer, F. A. Drews, and D. J. Crouch, "A comparison of the cell phone driver and the drunk driver," The Journal of the Human Factors and Ergonomics Society, vol. 48, pp. 381-391, 2006.

[22] S. P. McEvoy, M. R. Stevenson, and M. Woodward, "Phone use and crashes while driving: A representative survey of drivers in two Australian states," Medical Journal of Australia, vol. 185, pp. 630-634, 2006.

[23] Department for Transport. (September 2011). Reported Road Casualties in Great Britain 2010 Annual Report. [Online]. Available: http://assets.dft.gov.uk/statistics/releases/roadaccidents-and-safety-annual-report-2010/rrcgb2010-00.pdf

[24] Institute of Alcohol Studies. (August 2010). IAS Fact SheetDrinking and Driving. [Online]. Available: http://www.ias.org.uk/resources/factsheets/drink_driving.pdf

[25] Y. Li, D. Xie, G. Nie, and J. Zhang, "The drink driving situation in China," Traffic Injury Prevention, vol. 13, no. 2, pp. 101-108, March 2012.

[26] A. Sen, "Do stricter penalties or media publicity reduce alcoho consumption by drivers?" Canadian Public Policy/Analyse de Politiques, vol. 31, no. 4, pp. 359-379, 2010.

[27] SWOV. (June 2010). Police enforcement and driving speed, in Institute for Road Safety Research, Leidschendam. The Netherlands. [Online]. Available: http://www.swov.nl/rapport/Factsheets/UK/FS_Surveillance.pdf 